\title{
Significance of climate and hydrochemistry on shape variation - a case study on Neotropical cytheroidean Ostracoda
}

\author{
Claudia Wrozyna ${ }^{1,2}$, Thomas A. Neubauer ${ }^{3,4}$, Juliane Meyer ${ }^{1}$, Maria Ines F. Ramos ${ }^{5}$, and Werner E. Piller ${ }^{1}$ \\ ${ }^{1}$ Institute of Earth Sciences, NAWI Graz Geocenter, University of Graz, 8010 Graz, Austria \\ ${ }^{2}$ Institute for Geophysics and Geology, University of Leipzig, 04109 Leipzig, Germany \\ ${ }^{3}$ Department of Animal Ecology \& Systematics, Justus Liebig University, 35392 Giessen, Germany \\ ${ }^{4}$ Naturalis Biodiversity Center, Leiden, 2300 RA, the Netherlands \\ ${ }^{5}$ Coordenação de Ciências da Terra e Ecologia, Museu Paraense Emílio Goeldi, 66077-830, Brazil
}

Correspondence: Claudia Wrozyna (claudia.wrozyna@uni-leipzig.de)

Received: 13 September 2017 - Discussion started: 10 November 2017

Revised: 21 August 2018 - Accepted: 24 August 2018 - Published: 14 September 2018

\begin{abstract}
How environmental change affects a species' phenotype is crucial not only for taxonomy and biodiversity assessments but also for its application as a palaeo-ecological and ecological indicator. Previous investigations addressing the impact of the climate and hydrochemical regime on ostracod valve morphology have yielded contrasting results. Frequently identified ecological factors influencing carapace shape are salinity, cation, sulfate concentrations, and alkalinity. Here, we present a thorough approach integrating data with the carapace outline and surface details of the ubiquitous Neotropical cytheroidean ostracod species Cytheridella ilosvayi, as well as several climatic and hydrochemical variables, in order to investigate a potential link between morphology and environmental conditions. A recent study previously demonstrated considerable biogeographical variation in valve morphology among Floridian, Mexican and Brazilian populations of this species. We hypothesize that the climatic differences between the regions it inhabits and associated differences in hydrochemical regimes have influenced valve morphology and eventually led to biogeographically distinctive groups. Generalized least-squares Procrustes analyses based on outline and structural features were applied to the left and right valves of adult females and males. The analyses identified relative carapace length and shape symmetry as most important morphological characteristics representing shape differences across all datasets. Two-block partial least-squares analyses and multiple regressions indicate strong relationships between morphological and environmental variables, specifically with temperature season-
\end{abstract}

ality, annual precipitation and chloride and sulfate concentrations. We suggest that increased temperature seasonality slowed down growth rates during colder months, potentially triggering the development of shortened valves with welldeveloped brood pouches. Differences in chloride and sulfate concentrations, related to fluctuations in precipitation, are considered to affect valve development via controlling osmoregulation and carapace calcification. The factors identified by our analyses represent hitherto unknown drivers for ostracod ecophenotypy in other species and therefore suggest that environmental predictors for morphological variability are not consistent across non-marine ostracods.

\section{Introduction}

Understanding how species respond to environmental change is crucial for their application as proxies for past climate fluctuations as well as in forecasting the future dynamics and distributions of species. Morphological diversity represents a key feature of the interpretation of faunal changes (Wagner and Erwin, 2006) and ecological shifts (Mahler et al., 2010) and prompts discussions about speciation and extinction processes over time (e.g. Ciampaglio, 2004). Differences in shape and size among species have been shown to relate to changes of environmental parameter, in particular, differences in temperature across various clades (e.g. Loehr et al., 2010; Maan and Seehausen, 2011; Danner and Greenberg, 2015). Within freshwater invertebrates, ecophenotypic 
response has been documented for a variety of species, both recent and fossil (e.g. Hellberg et al., 2001; Zieritz and Aldridge, 2009; Inoue et al., 2013; Neubauer et al., 2013; Clewing et al., 2015).

Ostracods represent a popular proxy group for climate and ecosystem changes due to their occurrence in various habitats, ranging from most inland waters to marine and interstitial and even semiterrestrial and terrestrial environments (e.g. Horne, 2005). Their distribution is controlled by ecological factors such as salinity, temperature, and ion composition of the ambient water (e.g. Ruiz et al., 2013). The study of ecophenotypic variation in response to environmental change (Anadón et al., 2002; Frenzel et al., 2012; Fürstenberg et al., 2015; van der Meeren et al., 2010) demonstrates another approach using ostracods for palaeoenvironmental studies. Due to their calcitic valves, they have an excellent fossil record and are utilized as palaeoenvironmental and biostratigraphic indicators (Anadón et al., 2002). A number of studies have shown that ornamentation, noding, sieve pore shape, and carapace size are linked to environmental factors, e.g. salinity, temperature, water depth, and nutrient availability (van Harten, 1975; Yin et al., 1999; Majoran et al., 2000; van Harten, 2000; Anadón et al., 2002; Frenzel and Boomer, 2005; Medley et al., 2007; Marco-Barba et al., 2013; Meyer et al., 2016; Boomer et al., 2017). Especially with the rise of morphometric techniques, investigations dealing with carapace shape variation in relation to environmental variables have also increased (Yin et al., 1999; Baltanas et al., 2002; van der Meeren et al., 2010; Ramos et al., 2017; Grossi et al., 2017). Yet, the use of morphological data, even those based on morphometric analyses (Baltanas et al., 2002, 2003; van der Meeren et al., 2010; Grossi et al., 2017), has been restricted to either landmark-based or outline-based studies but has rarely used a combination of both (e.g. Ramos et al., 2017). Few studies integrate geographic gradients into their statistical analyses and corresponding climate variables or a reduced number of predictor variables. Moreover, shapeenvironment relationships are commonly identified based on simple linear regressions or qualitative observations on multivariate ordination methods.

Here, we apply a thorough approach integrating morphometric data from carapace outline and surface details, as well as several climatic and hydrochemical variables, in order to investigate a potential link between morphology and environmental conditions. The subject of study is the valves of the Neotropical cytheroidean ostracod species, Cytheridella ilosvayi. Studies by von Daday (1905) and Wrozyna et al. (2016, 2018a) already demonstrated considerable biogeographical variation in valve morphology among Floridian, Mexican, and Brazilian populations of that species. Morphological differences in populations of $C$. ilosvayi are discernible in both valves and appendages, adult and juvenile (A-1 to A3) stages, and across sexes, suggesting that morphological divergence is a result of long-term biogeographic isolation (Wrozyna et al., 2018b). While the morphological aspects of the biogeographic variability in C. ilosvayi are well understood, the causes for the regional differences have not been investigated. We hypothesize that the climatic differences between the regions inhabited by Cytheridella ilosvayi and the associated differences in hydrochemical regimes have influenced valve morphology and finally led to biogeographically distinctive groups. We apply two-block partial least-squares analyses and multiple regression analyses in order to test for covariation between the two sets of parameters (morphology, environment) and to identify the morphological characteristics and environmental variables that contribute most to the relationship. This approach is new to the research of ecophenotypy in ostracods for the following reasons: the investigation of the relationships between shape variations and environmental conditions is based on (1) a dataset covering a supra-regional geographical scale that coincides with the geographical range of Cytheridella, (2) environmental variables including local hydrochemical data and regional climatic data, (3) morphometric data that are based on a combination of landmarks and semilandmarks, including the carapace outline and positions of pore tubules on the surface of the carapaces, and (4) the identification of environmental variables that covary with morphological changes are based on multivariate statistical analyses.

\section{Material and methods}

\subsection{Material}

Specimens of C. ilosvayi derive from several sampling campaigns in Florida, Mexico, and Brazil during 2009-2015 (Fig. 1). A detailed list of the sampled localities is available in Table S1. Only adult valves were utilized in this study, providing a sufficient number of left and right valves for both sexes. Right and left valves were investigated separately due to dimorphism in size and shape (Wrozyna et al., 2014). Aside from this, females and males were analysed separately because a large part of inter-valve variation has been shown to depend on sexual differences (such as the presence of brood pouches in females; Wrozyna et al., 2016).

\subsection{Predictor variables}

Altogether, 15 variables were included in the analyses. Simultaneously to water sampling, field variables (electrical conductivity, water temperature and $\mathrm{pH}$ ) were measured in situ at all sample sites using a WTW multi-sensor probe (Multi 3420 Set C). Water samples were taken with plastic bottles, promptly filtrated using a syringe filter with a filter pore size of $0.45 \mu \mathrm{m}$, and stored in a freezer until analysis. Major ions were measured at the laboratory centre of Joanneum Research in Graz using ion chromatography (Dionex ICS-3000). As the variables measured per sampling station only provide a snapshot of the local ecological conditions, the set of variables was supplemented with bioclimatic data 


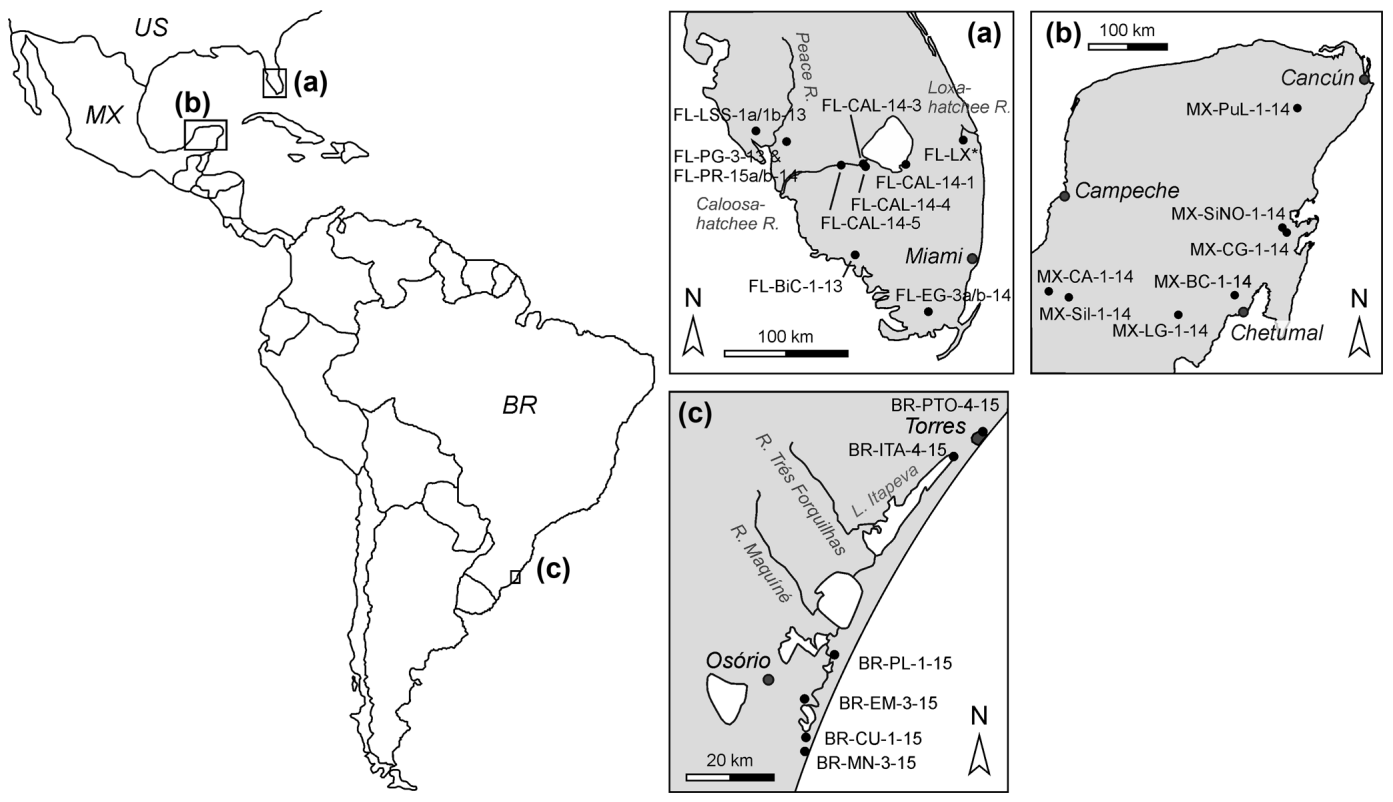

Figure 1. Geographic overview of the sampled populations (modified from Wrozyna et al., 2016). The label FL-LX* in map A comprises samples FL-LX-1-14 to FL-LX-6-14. For details, see Table S1 in the Supplement.

from the WorldClim database (WorldClim, 2017), providing data on monthly and yearly scales. From the many variables available, we included the annual mean temperature in ${ }^{\circ} \mathrm{C}$ (BIO1), mean diurnal range in ${ }^{\circ} \mathrm{C}(\mathrm{BIO} 2$; mean of monthly maximum-minimum temperature), temperature seasonality in ${ }^{\circ} \mathrm{C}(\mathrm{BIO} 4$; standard deviation $\times 100)$, annual precipitation in $\mathrm{mm}$ (BIO12) and precipitation seasonality (BIO15; coefficient of variation), each with a spatial resolution of 30 . We chose not to include all bioclimatic variables because many of them are highly correlated, causing issues for the regressions. Bioclimatic variables and occurrence data were linked in ESRI ArcGIS v. 10.4 with the tool "Extract Multi Values to Points". Environmental variables are provided in Supplement S2.

\subsection{Methods}

\subsubsection{Generalized Procrustes analysis}

Valve morphology was captured using a combination of landmarks and semilandmarks. Eight landmarks (LMs) were chosen to characterize anterior pore tubules (LM 1-5, type I) and the dorsal dip point of the posterior curvature (LM 6, type II) as well as to delimitate maximum anterior and posterior curvatures (LM 7-8, type III). The carapace outline was defined by two curves between LM 7 and 8, each comprised of 30 equidistantly spaced semilandmarks (see also Wrozyna et al., 2016). All points were set on digitized SEM images using the program TpsDig v. 2.17 (Rohlf, 2013). The sliders file determining sliding direction of the semilandmarks during the Procrustes alignment was created in TpsUtil v. 1.58
(Rohlf, 2015). A generalized least-squares Procrustes analysis, computing consensus configuration, partial warps and relative warps (RWs), was performed using the program TpsRelw v. 1.65 (Rohlf, 2016). Thin-plate spline deformation grids were used to visualize deviations of selected configurations from the mean and to identify morphological characteristics that account for differences among geographic regions. For details on the method see Rohlf and Slice (1990) and Bookstein (1996).

We ran preliminary analyses for each dataset to identify major outliers that may bias the morphometric analyses by overemphasizing particular directions in the morphospace (and associated morphological characteristics). Such a distortion may severely impede the sound interpretation of follow-up statistical analyses.

\subsubsection{Statistics}

In order to study the covariance between shape variation and environmental variables, two-block partial leastsquares (PLS) analyses were performed using the software PAST 3.18 (Hammer et al., 2001). A big advantage over other ordination methods such as principal components analysis, this method disregards inter-block variation that may mask between-block covariance (Mitteroecker and Bookstein, 2008, 2011). Using all RWs in the PLS analysis might severely bias the pattern since, contrary to their descending significance in terms of explaining shape variation, they would be treated equally by the analysis. Therefore, we restricted the morphological block to RW 1-20, which account for at least $98.6 \%$ of the total shape variations in 
(a)
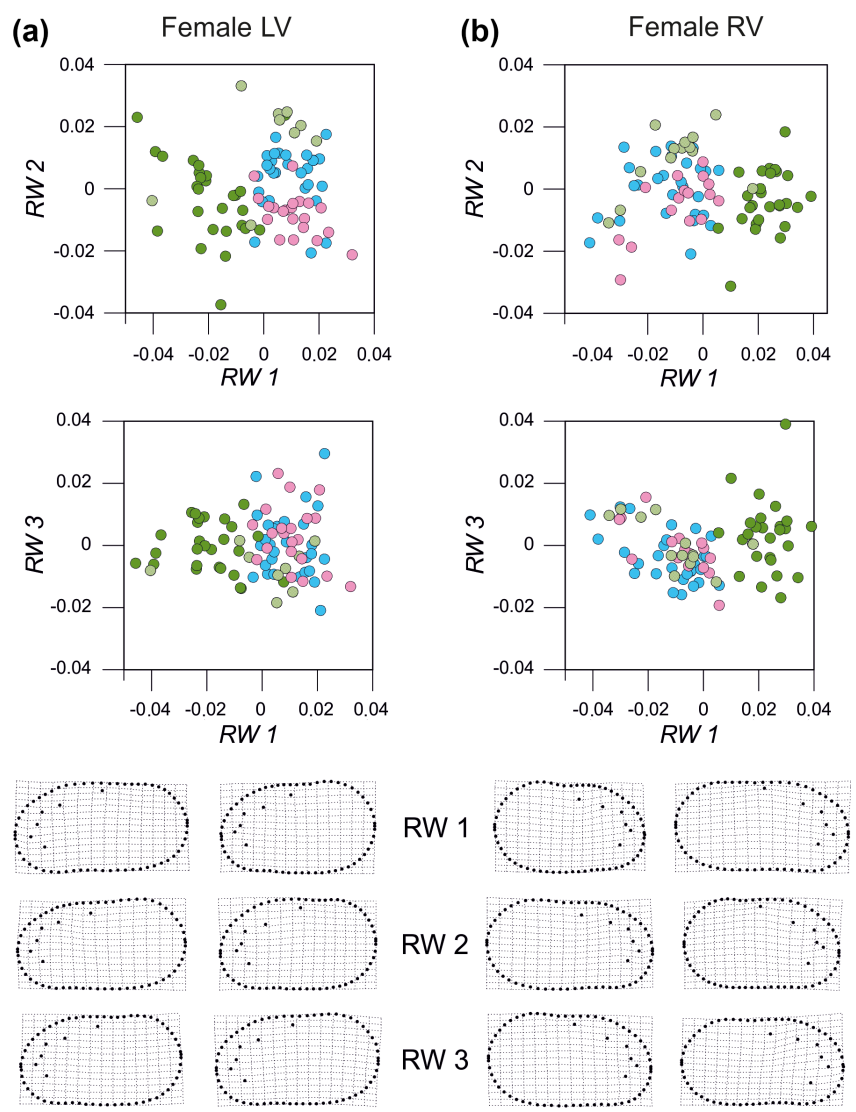

Min
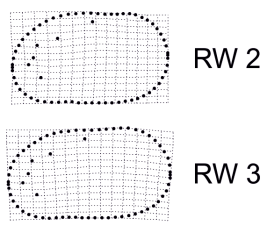

Max

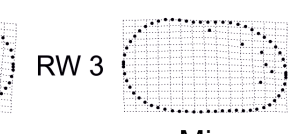

Min
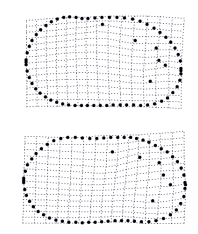

$\operatorname{Max}$

Figure 2. Relative warp analyses of left (a) and right (b) valves of females of the first three warps and the associated thin-plate splines at minimum and maximum scores. Colours refer to the different regions (blue - Florida, green - Mexico, light green - Lake Punta Laguna, pink - Brazil).

all four datasets. The environmental variables were $\log 10$ transformed to constrain the orders of magnitude involved. PLS analyses were computed based on correlation matrices.

The PLS analysis provides an idea of the overall strength of the relationships between shape and environment. To identify the parameters that affect specific morphological traits or combination of traits, multiple regression analyses were conducted on selected RWs in the statistical environment R v. 3.3.2 (R Core Team, 2016). Only warps (1) along which biogeographic differentiation was observed, (2) with an amount of shape variation higher than $10 \%$ of the total variation, and (3) with PLS loading values higher than the mean loading value (based on absolute values) were considered. These selection criteria were chosen in order to prevent the misinterpretation of seemingly strong relationships between shape and environmental variables. Since the environmental parameters are likely to be highly correlated, eventual regression models including all variables might be strongly skewed and susceptible to misinterpretation. Therefore, we employed a stepwise selection of variables based

on the variance inflation factor (VIF), which is an estimator of multicollinearity among variables (Quinn and Keough, 2002). As a rule of thumb, VIF values greater than 10 indicate the presence of multicollinearity (Quinn and Keough, 2002); some authors even consider values above 5 evidence of collinearity (Heiberger and Holland, 2004). The applied function iteratively removes collinear variables by calculating the VIF of variables against each other (for the script, see Ijaz, 2013); R package "fmsb" v. 0.5.2 (Nakazawa, 2015) is required for this procedure. VIF values were calculated with package "HH" v. 3.1-32 (Heiberger, 2016). To enhance the models further, multiple regressions using backward stepwise selection through an evaluation based on the Akaike information criterion (AIC) were performed with the remaining set of factors. The normality of model residuals was tested with the Shapiro-Wilk tests. In case normality was not achieved, residual distributions were assessed qualitatively using Q-Q plots; only if the majority of cases matched the expected distribution was a model considered significant. Finally, we used the R package "hier.part" v. 1.0-4 (Walsh and Mac Nally, 2013) to evaluate the independent contribution of each predictor to the reduced models.

\section{Results}

The relative warp analysis (RWA) yielded different results for males and females, while patterns were largely consistent within sexes (Figs. 2, 3). Along the first three relative warps, Mexican females have little overlap with Brazilian and Floridian ones. Only some of the specimens from Punta Laguna in northern Yucatan seem to be morphologically closer to the Floridian group and cluster apart in the analyses of both valves. Brazilian and Floridian specimens have a distinctly higher overlap and differentiate only little along RW 2. A clear differentiation within both clusters, like in the Mexican group, is lacking. Group differentiation in male valves is quite the contrary: Floridian specimens have little overlap with Brazilian ones in both valves along RW 1, while Mexican specimens are hardly separable from either group along any of the first 3 RWs. However, the differentiation between some Punta Laguna valves and the remaining Mexican carapaces along RW 1 is comparable to the patterns observed for females. Mexican and Brazilian males show slight biogeographic differentiation along RW 2 (left valves) and RW 3 (right valves), respectively. No clustering is observed for higher warps in either sex or valve.

Similar to the patterns posed by the scatter plots, the thinplate splines indicate that shape variation along the RWs is largely consistent within valves but differs slightly between sexes. Here we discuss only axes along which biogeographic discrimination is observed (see Wrozyna et al.,2016, for inter-group variations). The most important morphological characteristic representing shape differences along RW 1 in both females and males and right and left valves is relative 
(a)
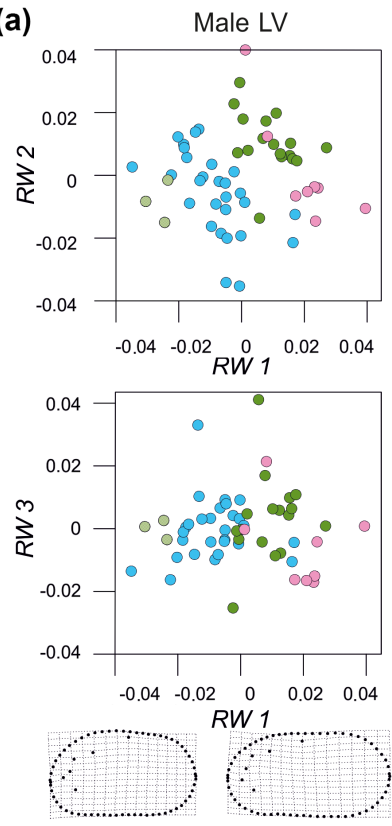

RW 1
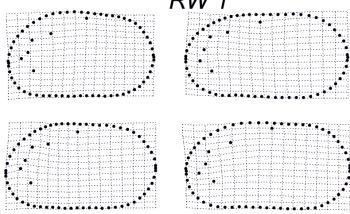

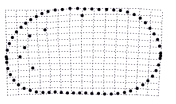

Min (b)
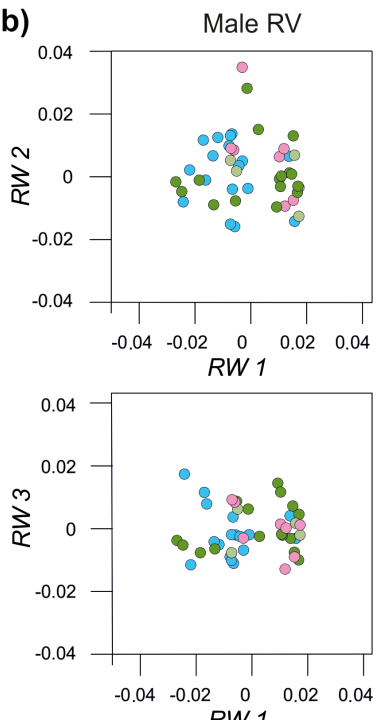

RW 1

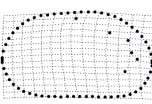

RW 1

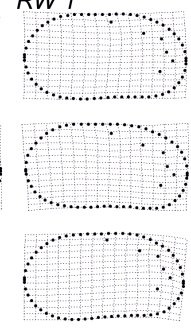

$\operatorname{Max}$
Figure 3. Relative warp analyses of left (a) and right (b) valves of males of the first three warps and the associated thin-plate splines at minimum and maximum scores. Colours refer to the different regions (blue - Florida, green - Mexico, light green - Lake Punta Laguna, pink - Brazil).

carapace length (Figs. 2, 3). However, the exact expression differs between sexes: valve outline in males varies between elongated elliptical and short asymmetrical with a slightly inflated anterior part, and between elongated elliptical and short asymmetrical with distinctly inflated posterior region (i.e. brood pouch) in females. In addition to outline differences, the position of the anteriormost pore conulus (LM 2) shifts in the dorsoventral direction consistently in both valves and sexes. In females, also the position of the dorsal dip point of the posterior curvature (LM 6) varies in the dorsoventral direction. The shape variation along RW 2 is similar for females as in RW 1 but with a different combination of traits: negative scores correspond to elongated valves with inflated posterior and slightly shifted LM 2 and LM 6 in the dorsoventral direction. In male Cytheridella, only left valves show weak biogeographic differentiation along RW 2, representing shape differences from elongated elliptical to slightly asymmetrical with a higher dorsal margin, and the dorsal dip point of the posterior curvature (LM 6) shifts towards the posterior region. The only differentiation along RW 3 is for male right valves, corresponding mostly to shell elonga-

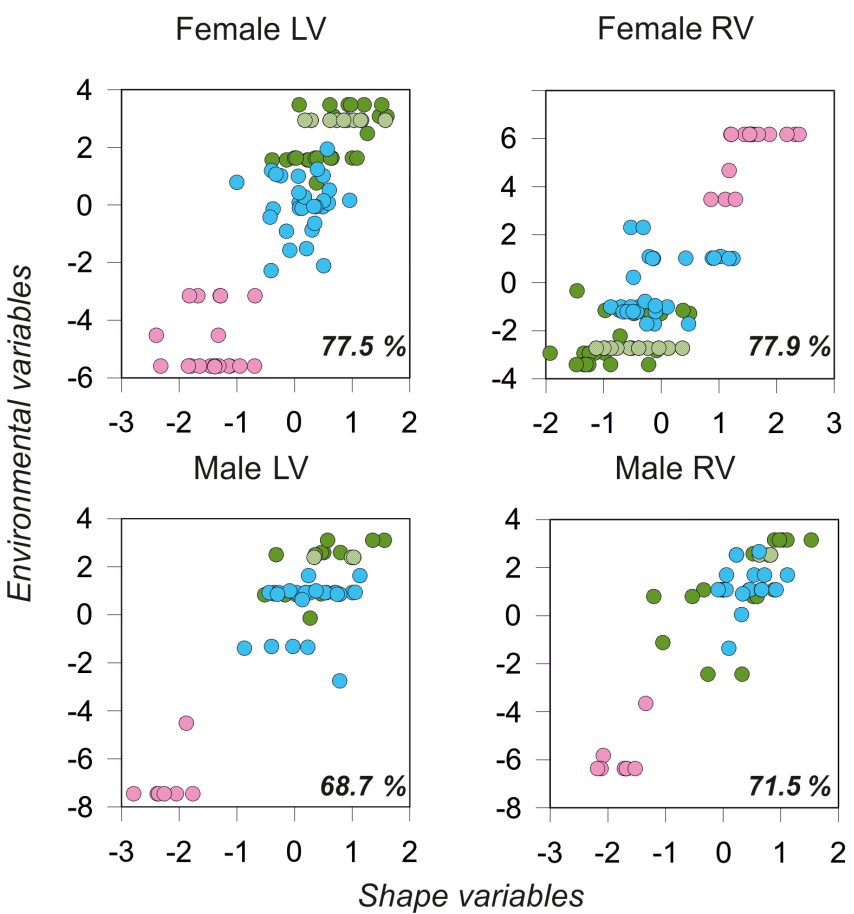

Figure 4. First axis of the PLS analysis of carapace shape and environmental variables. Colours refer to the different regions (blue Florida, green - Mexico, light green - Lake Punta Laguna, pink Brazil).

tion and to a lesser extent the relative positions of the pore conules. The relative warp scores of all datasets are provided in Table S2.

The PLS analyses indicate relationships between morphological and environmental variables, yet with different results for males and females. The first PLS axis explains between $68.7 \%$ and $77.9 \%$ of the total variation, whereas values are consistently higher for females (LV: $77.5 \%$; RV: $77.9 \%$ ) than for males (LV: $68.7 \%$; RV: $71.5 \%$ ). In all four analyses, Brazilian specimens are widely separated from Floridian and Mexican ones along PLS axis 1, corresponding to a clear differentiation in both environmental and morphological scores. The left valves of females and the left and right valves of males of Brazilian specimens exhibit negative scores on both PLS axes corresponding to shape and environmental variables. Females display inverse distributions for Brazilian and Mexican specimens. Floridian and Mexican groups have little but consistent overlap in all analyses, while the specimens of Florida tend to have smaller variation ranges than Mexican groups (Fig. 4). Permutation tests indicate, however, that PLS analyses are hardly significant for male valves (LV: $P=0.126$, RV: $P=0.135$ ). Yet, the low significance levels do not necessarily imply the lack of a relationship between shape and environment; rather, they witness the difficulties in finding clear relationships in multifactorial analyses. In fact, the overall picture provided by the PLS analysis 
might mask individual relationships between selected shape traits and environmental parameters, which is why a closer look using multiple regressions is required. Nonetheless, the PLS analyses are useful in examining the overall strength of the relationships, which seem to be stronger and clearer in females than in males.

For PLS axis 2, few relationships between shape and environment are yielded for all four datasets, and none of them are significant (see Table S3).

The loadings for morphological variables in the PLS analyses yield constantly high values for RW 1; RW 2 shows loading values higher than the mean (based on absolute values) in all analyses except male right valves; RW 3, in turn, contributes above average to variation in all cases except female right valves. Other warps were not considered because of their minor influence on shape variation (low loading values) or the lack of biogeographic separation. See Table 1 for a summary of the results.

The following warps fulfil the selection criteria defined in "Methods" for consideration in the multiple regressions: RW 1 for all four datasets; RW 2 for female right and left valves; RW 3 for female left valves and male right and left valves. Hence, nine regression analyses were carried out. Shapiro-Wilk tests of model residuals indicate normality for four of the nine analyses (Table 1). An inspection of Q-Q plots yielded, however, that in all models the majority of cases match the expected distributions, which is why the remaining models are still considered significant (see Supplement Fig. S1). Eight out of nine models are significant $(P<0.05)$, while the model for RW 3 for male left valves is not $(P=0.074)$.

Only a limited set of predictor variables is retained out of the original 15 variables in each model after the elimination of collinear parameters and the backward stepwise selection (see Supplement Table 4). Seven parameters do not contribute to any models: These are $\mathrm{Na}^{+}, \mathrm{Ca}^{2+}, \mathrm{Mg}^{2+}$, $\mathrm{HCO}_{3}^{-}$, conductivity, mean annual temperature, and precipitation seasonality. Of the remaining factors, temperature seasonality is one of the most important predictors in almost all models, accounting for at least $28.7 \%$ in all models with RW 1. Temperature seasonality is highest in Florida, closely followed by Brazil, and considerably less in Mexico, reflecting the distinction between Mexican, Floridian, and Brazilian populations along RW 1. Similarly, annual precipitation and the anions $\mathrm{Cl}^{-}$and $\mathrm{SO}_{4}^{2-}$ contribute significantly to many models, corresponding to differences in the hydrological regimes. The $\mathrm{pH}, \mathrm{K}^{+}$, water temperature, and mean diurnal temperature range were less explanatory. It is noteworthy that anions, represented by $\mathrm{Cl}^{-}$and $\mathrm{SO}_{4}^{2-}$, are obviously much more important than cations.

\section{Discussion}

The link between shape variation and environmental conditions is a well-studied branch of ostracodology, but studies have yielded quite contrasting results. Frequently identified ecological factors are the salinity (Yin et al., 1999, 2001; Grossi et al., 2017) and hydrochemical regime, mirrored by the $\mathrm{Mg}^{2+}, \mathrm{Ca}^{2+}$ and $\mathrm{K}^{+}$contents (Ramos et al., 2017), or alkalinity and sulfate, respectively (van der Meeren et al., 2010). The morphological response to the same environmental factor may even differ between environments (e.g. Yin et al., 1999), complicating straightforward explanation models.

The deduction of general relationships between shape and environmental conditions is hampered due to different approaches, geographical areas and ranges, and different environmental datasets. Many studies are based on mesocosm experiments (e.g. Mezquita et al., 1999; Yin et al., 1999; van Harten, 2000; Frenzel et al., 2012). Although they play an important role in increasing our understanding of the ecophenotypic responses of ostracods to environmental changes, they cannot, by nature, cover the full range and interplay of natural conditions. Other authors studied field populations covering small geographical areas with high resolution (e.g. van der Meeren et al., 2010) or larger study regions with widespread sampling that did not match the distribution of the species involved (e.g. Baltanas et al., 2002; Ramos et al., 2015; Boomer et al., 2017). Our approach is the first that covers a supra-regional scale that coincides with the geographical range of the study taxon. Another novel contribution to the investigation of ecophenotypy is represented by the inclusion of climatic data, in contrast to many other approaches where datasets are often restricted to hydrochemical information. In contrast to climatic data, hydrochemical conditions usually vary on small spatial scales. Previous studies were therefore restricted to characterize local rather than regional effects of the environment on shape changes. It is known from several other organism groups that species may exhibit differences in sensitivity to the ecological conditions in their geographical ranges, since they have a higher sensitivity of range-edge populations than those nearer to the centre of the species' distribution (e.g. Mills et al., 2017). Thus, some environmental parameters that were identified in other studies as major controls on morphological changes (such as salinity) could be important on more restricted geographical scales due to a higher sensitivity of the local populations. The ecophenotypic response to changes of environmental conditions could vary along with the geographical scale. Our approach enables the investigation of the overall pattern of ecophenotypic responses to environmental change and minimizes local effects. 


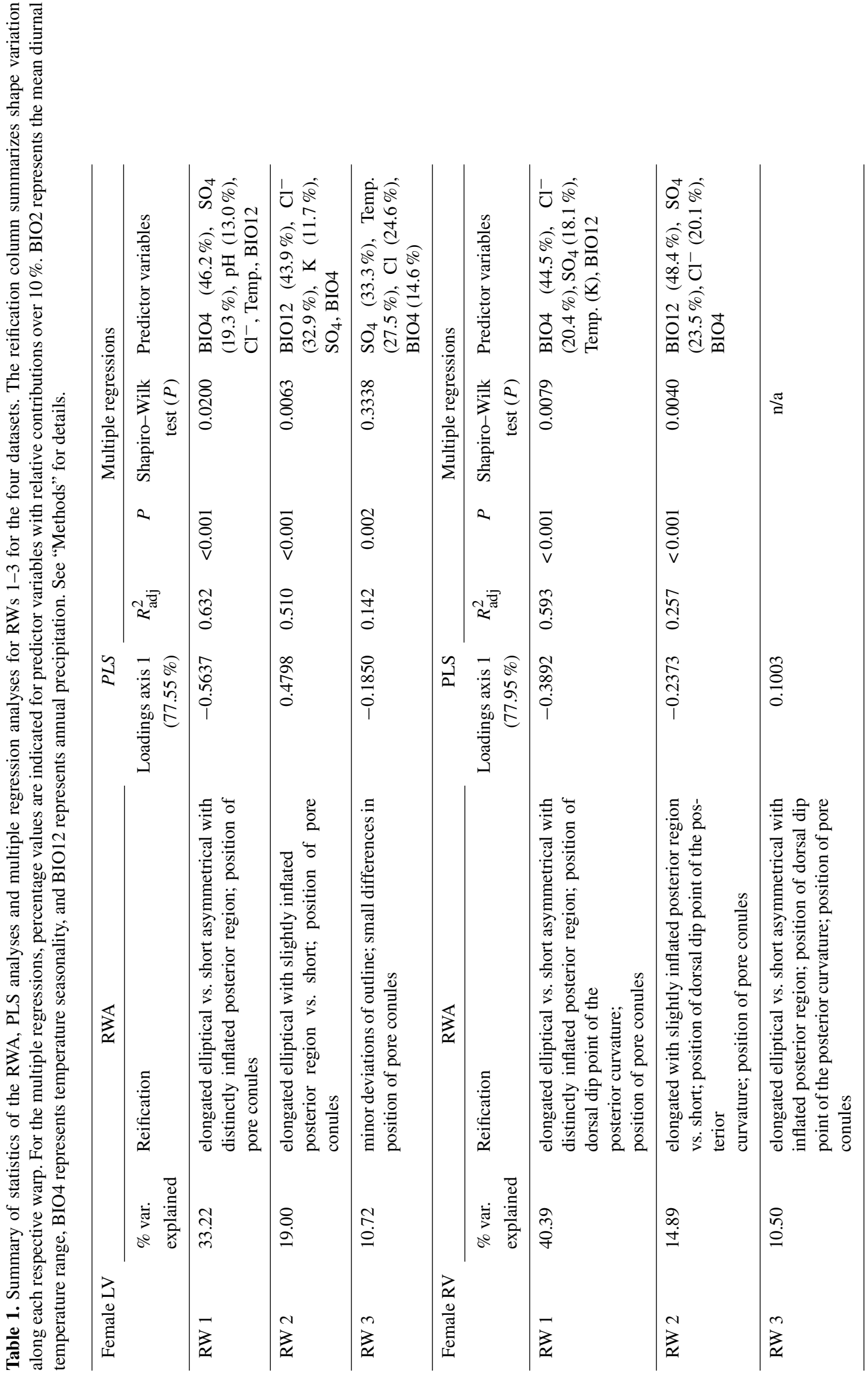




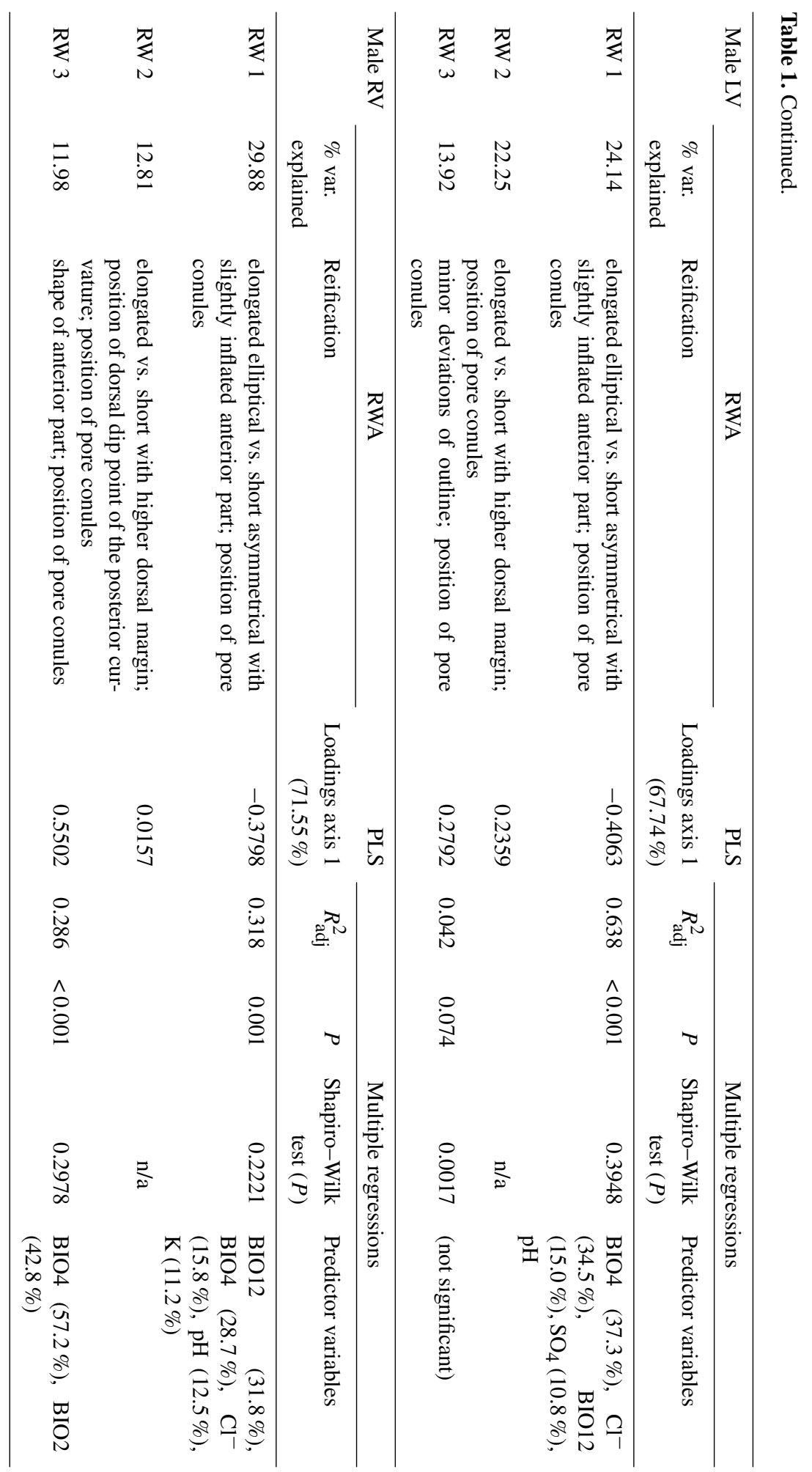




\subsection{Potential environmental drivers of valve shape variation}

So far, this approach has been the first to study the relationship between shape and the environment in an ostracod species that occurs in tropical and subtropical areas. However, little information is available regarding the biology of Cytheridella (e.g. Meyer et al., 2017), and the mechanisms that control the relationship between valve shape and environmental gradients are not understood at present. Like many non-marine ostracods, Cytheridella is characterized by a benthic life style. The growth and proliferation of an individual and a population, respectively, might benefit from changes in carapace shape with respect to different habitats. For instance, a more elongated shape could be advantageous in more densely vegetated environments because of increased motility. For the present study, we sampled various habitats within each region, which differed in vegetation cover and composition (Table S1). If shape differences were indeed functional adaptations to varying habitat conditions, we would expect a much higher morphological variability within each region and smaller differences between specimens from similar habitat types than shown by the analyses. Rather, we suppose that shape difference in Cytheridella ilosvayi has a physiological origin that mirrors the varying environmental conditions.

Variation in temperature seasonality, annual precipitation and anions $\left(\mathrm{Cl}^{-}, \mathrm{SO}_{4}^{2-}\right)$ explain a large portion of shape variation in Cytheridella, which is mostly related to relative carapace length and outline shape. Narrow, elongated shapes, such as those occurring in Mexico, correspond to relatively low seasonality and precipitation but high anion concentrations. Opposite conditions seem to favour the formation of short, asymmetrical valves typical for specimens from Florida and Brazil. Secondary shape variations differentiating between elongated valves with slightly wider posterior and short, symmetrical valves (i.e. RW2) are attributed to higher and lower annual precipitation, respectively.

The geographical range of Cytheridella coincides with the Neotropical region, which spans a wide latitudinal range from $\sim 30^{\circ} \mathrm{N}$ to $\sim 30^{\circ} \mathrm{S}$. This range involves a latitudinal decline in mean annual temperature, which mainly corresponds to differences in annual minimum temperature (Lewis, 1996). Florida and southern Brazil are characterized by higher annual temperature gradients compared to Mexico. Annual minimum and maximum temperatures range between 16 and 30 and 10 and $30^{\circ} \mathrm{C}$ in Florida and southern Brazil, respectively. Overall, minimum and maximum temperatures vary between 19 and $33^{\circ} \mathrm{C}$ (Climate-Data.org, 2017).

Temperature has a direct effect on other environmental parameters such as salinity and the oxygenation of the water. Water temperature is one of the most important variables affecting metabolism, oxygen consumption, growth, moulting, and the survival of crustaceans (Le Moullac and Haffner,
2000 , and references therein). The time span of ostracod life cycles varies from a few months to as long as four years, producing one or more generations per year (Horne, 2005). At least in temperate regions, the start of the reproductive period (and thus the moult cycle) is often related to temperature (Van Doninck et al., 2003). Meyer et al. (2017) recently found that populations of $C y$ theridella from Florida have defined calcification periods that are linked to local hydrological conditions.

Increases in temperature can result in significantly shortened intermoult periods, higher moulting rates (Roca and Wansard, 1997; Mezquita et al., 1999; Brylawski and Miller, 2006), increased growth increments (Martens, 1985; Iguchi and Ikeda, 2004), and a reduction in maturation time (Pöckl, 1992). We expect that a stronger temperature seasonality induced prolonged moult cycles in populations of C. ilosvayi by extending intermoult periods during colder seasons. We propose that the changed moult cycles affected calcification patterns and led to the observed differences in shape. Since the physiological processes involved in the secretion of ostracod valves are not well known (and not at all for Cytheridella), this hypothesis cannot be tested at present.

Precipitation causes declines in nutrients and promotes the physical disturbance of the water column (Figueredo and Giani, 2009). Moreover, changes in precipitation directly influence hydrochemical composition and the input of sediments, organic components, and contaminants as well as affecting the lake level (Mortsch and Quinn, 1996; Whitehead et al., 2009). This also includes indirect influences, e.g. those affecting aquatic plants, which represent important microhabitats and/or food sources (Lacoul and Freedman, 2006). The annual cycle of precipitation over most of South America is monsoon-like, with great contrasts between winter and summer (Grimm et al., 2007). The peak rainy season in the Brazilian sample region is during the austral winter. The rainfall is caused by frontal penetration associated with migratory extratropical cyclones (Grimm et al., 1998). The amount of rainfall in Yucatan is associated with the seasonal migration of the Intertropical Convergence Zone and to a lesser extent with spatially oriented tropical convective activity (e.g. Hodell et al., 2008). Florida, in particular southern Florida where most of our samples are derived from, receives maximum precipitation during the summer in the Northern Hemisphere due to convectional and tropical storms (Schmidt et al., 2001). The annual precipitation amounts for the sampled areas are higher on average in Brazil at 1396-1492 mm per year compared to Florida and Yucatan, with 1185-1430 and $1125-1359 \mathrm{~mm}$, respectively. Since the annual precipitation amounts of the regions are very similar, it might be more plausible that precipitation seasonality has an influence on the carapace shape of Cytheridella through seasonally restricted nutrient inputs or changes in the hydrochemistry. Annual precipitation should therefore be considered with caution since it is difficult to deduce a causal relationship with the carapace shape. 
The ionic composition of the host water is vital for the calcification and growth rates of ostracods (Mezquita et al., 1999). The relationship between hydrochemistry and phenotypic variability is poorly understood, however. A study from Kim et al. (2015) shows that increased levels of $\mathrm{pH}$ account for decreased carapace growth rates, i.e. prolonged intermoult periods, and smaller carapaces. Carapace shape differences have been moreover associated with changes in $\mathrm{Ca}^{2+}, \mathrm{Mg}^{2+}$, and $\mathrm{pH}$ (Ramos et al., 2017). Our analyses, however, revealed correlations neither with ions related to formation of carbonate, such as $\mathrm{HCO}_{3}^{-}, \mathrm{Ca}^{2+}$, and $\mathrm{Mg}^{2+}$, nor with $\mathrm{pH}$. Only chloride and sulfate contents significantly correlate with carapace shape variation.

Natural sources of $\mathrm{Cl}^{-}$in freshwater derive from marine sprays transferring $\mathrm{NaCl}$ into the atmosphere and are either transported as aerosol by wind or are washed out by precipitation and the weathering of rocks. Additionally, large amounts of chloride are derived anthropogenically from farming and waste-water production (Müller and Gächter, 2012). Sulfate can be derived from the runoff from mining and agricultural areas, the mobilization from pyrite deposits by oxygen intrusion during desiccation, and the weathering of rocks containing sulfur (Holmer and Storkholm, 2001; Lamers et al., 2002). Sulfate contents in groundwater and surface water result from dissolution of gypsum and anhydrite occurrences (Perry et al., 2002) and from mixing with seawater (Sacks et al., 1995). In Yucatan, a gypsum-rich stratigraphic unit occurs, resulting in a solution-enhanced subsurface drainage pathway for a broad region extending along the eastern coast and from the east to the west in the southern part of the region (Perry et al., 2009). The chloride content of groundwater is the result of mixing with seawater (Mondal et al., 2010). Additionally, a $\mathrm{Cl}^{-}$gradient extends from southeast to northwest, resulting in generally higher chloride contents (Perry et al., 2009). Concentration gradients of $\mathrm{SO}_{4}^{2-}$ and $\mathrm{Cl}^{-}$in Florida occur from inland to coastal areas as well as in deep water (Sacks et al., 1995), explaining the relatively higher amount of chloride and sulfate. The comparably low values for south Brazilian sampling locations are not surprising, given that such coastal bodies of water are often fed by groundwater (Santos et al., 2008) that predominately consists of bicarbonate water and low chloride and sulfate contents (Gianesella-Galvão and Arcifa, 1988; Viero et al., 2009). The detected relationship between morphotypes and chloride and sulfate contents could thus mirror the hydrochemical compositions resulting from the different hydrogeological conditions of the regions.

Van der Meeren et al. (2010) found ostracod valve shape variability to significantly correlate with the ratio between alkalinity and sulfate. As the ratio inversely related to solute concentration, the authors hypothesized that carapace shape may be linked to changes in the lake water balance, relative climatic moisture, or changes in the sources of solutes delivered to the environment. Varying anionic composition has also been considered to affect osmoregulation and calcification (Mezquita et al., 1999). As hyperosmotic organisms, freshwater ostracods pump ions inwards (mainly $\mathrm{Na}^{+}$and $\mathrm{Cl}^{-}$) and water outwards to maintain a stable internal ionic concentration higher than that of the ambient water (Weihrauch et al., 2004). Chloride is obtained from the environment through a $\mathrm{HCO}_{3}^{-} / \mathrm{Cl}^{-}$antiport pump. The organism needs to precipitate calcite while also pumping $\mathrm{HCO}_{3}^{-}$outwards to maintain the internal $\mathrm{Cl}^{-}$concentration (Mezquita et al., 1999). These authors assumed that even small genetic differences affect varied ecophysiological responses to temperature and water chemistry, which may be a key factor in the explanation of the different biogeographical patterns of non-marine ostracods. The trade-off between ionic regulation and calcification is especially considered to play a key role in ostracod speciation (Mezquita et al., 1999).

One of the best-studied phenomena in ostracods is variable noding (hollow outward flexions on the lateral surfaces on the valves) in Cyprideis (e.g. Vesper, 1975; van Harten, 2000). A connection between node formation and salinity was noted early, but the reported salinity limits are partly contradictory (Keyser and Aladin, 2004). Frenzel et al. (2012) deduced from a combination of mesocosm cultures and field studies that noding in Cyprideis torosa valves is pathological and caused by osmotic problems in lower salinities and the lack of $\mathrm{Ca}^{2+}$ during moulting. From the same species it is known that increased salinity corresponds with a decreased proportion of rounded sieve pores in the valves (Frenzel et al., 2017). Considering that the variability of discrete valve traits such as noding or sieve pore shape is related to complex physiological processes, we suggest that the relationship between carapace shape and ionic composition detected by our analyses could be a result of the complex interplay of different physiological processes affecting valve calcification. Understanding the physiological processes involved requires more detailed studies.

\subsection{Genetic diversity or ecophenotypic plasticity?}

Phenotypic variation in ostracods is considered to reflect either genotypic or ecophenotypic variability or a combination of both (Martens et al., 1998; Yin et al., 1999; Anadón et al., 2002; Frenzel and Boomer, 2005; Boomer et al., 2017; Grossi et al., 2017). A recent study on the valve outline variability of a non-marine ostracod demonstrated that differences in carapace shape do not correspond to genetic clades (Koenders et al., 2016). However, caution is advised when comparing patterns among species, since different species react differently and have varying potentials for ecophenotypic variation (Anadón et al., 2002; Frenzel and Boomer, 2005). The relationship between genotype and environment might differ among species, geographical regions, and over time (see, e.g. Sanchez-Gonzalez et al., 2004; Koenders et al., 2016). Our results clearly imply that morphological disparity in Cytheridella is controlled by environmental factors. However, the distribution and the variation range of regional 
clusters reveal some opposing implications. For instance, a part of the Mexican population comprises specimens with similarly shortened valves, which are similar to those found in the Floridian group. Both shortened and elongated morphotypes co-occur in one lake (i.e. Punta Laguna) (Wrozyna et al., 2018a). On the one hand, this co-occurrence could suggest the presence of microhabitats with specific environmental conditions, suggesting different impacts on valve calcification in the very same ecosystem. On the other hand, this discrepancy might be considered as evidence for genetic differentiation. An integrated study combining genetic and morphometric data is required to further explore this case.

\section{Conclusions}

The comparison of our results with a large number of previous studies speaks to the difficile nature of the ecophenotypic response to varying climatic and ecological conditions in freshwater ostracods. Shape variation in Cytheridella, mostly related to relative carapace length and outline shape, is mainly explained by temperature seasonality, annual precipitation, and chloride and sulfate compositions. Increased temperature seasonality, a characteristic of Florida and south Brazil, is considered to account for slower growth rates during colder months and may have triggered the development of shortened valves with well-developed brood pouches. We propose that differences in chloride and sulfate concentrations, which are related to fluctuations in precipitation, might have affected valve development by controlling osmoregulation and carapace calcification. However, these explanation models are tentative, as physiological studies on the influence of changing ecological conditions in non-marine ostracods are still scanty. A more detailed picture of its effects will require mesocosm experiments and field observations.

Temperature (per se), salinity (expressed as electrical conductivity), and $\mathrm{pH}$ have had surprisingly little or no effects on shape variation in C. ilosvayi, although these factors have been discussed as important drivers of ostracod ecophenotypy that variably affect size, ornamentation, and shape. The discrepancies in explanation models suggest that environmental predictors for valve shape are not consistent across non-marine ostracods. The nature of the phenotypeenvironment relationship likely depends on the choice of the model taxon and ecosystem. On a larger scale, this lack of a general pattern complicates the reconstruction of palaeoenvironments based on ecophenotypic variation.

Data availability. All data are presented within the paper or in the Supplement. Bioclimatic data are provided by the WorldClim database (WorldClim, 2017).

The Supplement related to this article is available online at https://doi.org/10.5194/bg-15-5489-2018-supplement.
Author contributions. CW, JM, and WEP carried out sampling of Cytheridella populations. CW and JM prepared ostracod material for morphometric analyses. TAN performed statistical analyses. The paper was written by CW and TAN. MIFR contributed to the discussion of the results and provided taxonomic advice.

Competing interests. The authors declare that they have no conflict of interest.

Acknowledgements. We are grateful to Norma Luíza Würdig (Universidade Federal do Rio Grande do Sul and personnel at CECLIMAR in Tramandai, Brazil) for offering their facilities. We thank Øyvind Hammer (University of Oslo) for helping with the permutation tests. We also want to thank Thomas Wagner (University Graz) for his helpful comments in the hydrological and hydrogeological discussion. Financial support was provided by the Austrian Science Fund (grant number P26554). Thomas A. Neubauer was supported by a Just'us postdoctoral fellowship granted by the University of Giessen and an Alexandervon-Humboldt Fellowship for postdoctoral researchers. We thank three anonymous reviewers for their helpful comments.

Edited by: Nobuhito Ohte

Reviewed by: three anonymous referees

\section{References}

Anadón, P., Gliozzi, E., and Mazzini, I.: Palaeoenvironmental Reconstruction of Marginal Marine Environments From Combined Palaeoecological and Geochemical Analyses on Ostracods, in: The Ostracoda: Applications in Quaternary Research, edited by: Holmes, J. A. and Chivas, A. R., Geophys. Monogr. Ser., 131, 22-247, https://doi.org/10.1029/131GM12, 2002.

Baltanas, A., Alcorlo, P., and Danielopol, D. L.: Morphological disparity in populations with and without sexual reproduction: a case study in Eucypris virens (Crustacea: Ostracoda), Biol. J. Linn. Soc., 75, 9-19, 2002.

Baltanas, A., Brauneis, W., Danielopol, D. L., and Linhart, J.: Morphometric Methods For Applied Ostracodology: Tools for Outline Analysis Of Nonmarine Ostracodes, in: Bridging the Gap: Trends in the Ostracode Biological and Geological Sciences, edited by: Park, L. E. and Smith, A. J., Palaeont. Soc. Papers, 9, 101-118, 2003.

Bookstein, F. L.: Biometrics, biomathematics and the morphometric synthesis, B. Math. Biol., 58, 313-365, 1996.

Boomer, I., Frenzel, P., and Feike, M.: Salinity-driven size variability in Cyprideis torosa (Ostracoda, Crustacea), J. Micropalaeontol., 36, 63-69, https://doi.org/10.1144/jmpaleo2015-043, 2017.

Brylawski, B. J. and Miller, T. J.: Temperature-dependent growth of the blue crab (Callinectes sapidus): A molt process approach, Can. J. Fish. Aquat. Sci., 63, 1298-1308, https://doi.org/10.1139/f06-011, 2006.

Ciampaglio, C. N.: Measuring changes in articulate brachiopod morphology before and after the Permian mass extinction event: do developmental constraints limit morphological inno- 
vation?, Evol. Dev., 6, 260-274, https://doi.org/10.1111/j.1525142X.2004.04031.x, 2004.

Clewing, C., Riedel, F., Wilke, T., and Albrecht, C.: Ecophenotypic plasticity leads to extraordinary gastropod shells found on the "Roof of the World", Ecol. Evol., 5, 2966-2979, https://doi.org/10.1002/ece3.1586, 2015.

Climate-Data.org: Climate data for cities worldwide - ClimateData.org, available at: https://en.climate-data.org/, last access: 13 June 2017.

Danner, R. M. and Greenberg, R.: A critical season approach to Allen's rule: Bill size declines with winter temperature in a cold temperate environment, J. Biogeogr., 42, 114-120, https://doi.org/10.1111/jbi.12389, 2015.

Figueredo, C. C. and Giani, A.: Phytoplankton community in the tropical lake of Lagoa Santa (Brazil): Conditions favoring a persistent bloom of Cylindrospermopsis raciborskii, Limnologica, 39, 264-272, https://doi.org/10.1016/j.limno.2009.06.009, 2009.

Frenzel, P. and Boomer, I.: The use of ostracods from marginal marine, brackish waters as bioindicators of modern and Quaternary environmental change, Palaeogeogr. Palaeocl., 225, 68-92, 2005.

Frenzel, P., Schulze, I., and Pint, A.: Noding of Cyprideis torosa valves (Ostracoda) - a proxy for salinity? New data from field observations and a long-term microcosm experiment, Int. Rev. Hydrobiol., 97, 314-329, https://doi.org/10.1002/iroh.201211494, 2012.

Frenzel, P., Ewald, J., and Pint, A.: Salinity-dependent sieve pore variability in Cyprideis torosa: an experiment, J. Micropalaeontol., 36, 57-62, https://doi.org/10.1144/jmpaleo2016-009, 2017.

Fürstenberg, S., Frenzel, P., Peng, P., Henkel, K., and Wrozyna, C.: Phenotypical variation in Leucocytherella sinensis Huang, 1982 (Ostracoda): A new proxy for palaeosalinity in Tibetan lakes, Hydrobiologia, 751, 55-72, https://doi.org/10.1007/s10750-0142171-3, 2015.

Gianesella-Galvão, S. M. F. and Arcifa, M. S.: The ionic composition of ten reservoirs in southern Brazil, Rev. Hydrobiol. Trop., 21, 93-99, 1988.

Grimm, A. M., Ferraz, S. E. T., and Gomes, J.: Precipitation anomalies in Southern Brazil associated with El Niño and La Niña Events, J. Clim., 11, 2963-2880, 1998.

Grimm, A. M., Pal, J. S., and Giorgi, F.: Connection between Spring Conditions and Peak Summer Monsoon Rainfall in South America: Role of Soil Moisture, Surface Temperature, and Topography in Eastern Brazil, J. Clim., 20, 5929-5945, https://doi.org/10.1175/2007JCLI1684.1, 2007.

Grossi, F., Prato, S. D., and Gliozzi, E.: Is the occurrence of a sigmoidal ventral border in Cyprideis torosa (Jones) valves linked to salinity?: A morphometrical analysis approach, J. Micropalaeontol., 36, 70-79, https://doi.org/10.1144/jmpaleo2016018, 2017.

Hammer, Ø., Harper, D. A. T., and Ryan, P. D.: PAST: Palaeontological statistics software package for education and data analysis, Palaeontol. Electron., 4, 351 pp., 2001.

Heiberger, R. M.: HH: Statistical Analysis and Data Display: Heiberger and Holland: R package version 3.1-32, available at: http://CRAN.R-project.org/package=HH (last access: 4 December 2017), 2016.

Heiberger, R. M. and Holland, B.: Statistical analysis and data display: An intermediate course with examples in S-plus, R, and SAS, Springer, New York, 2004.
Hellberg, M. E., Balch, D. P., and Roy, K.: Climate-driven range expansion and morphological evolution in a marine gastropod, Science, 292, 1707-1710, https://doi.org/10.1126/science.1060102, 2001.

Hodell, D. A., Anselmetti, F. S., Ariztegui, D., Brenner, M., Curtis, J. H., Gilli, A., Grzesik, D. A., Guilderson, T. J., Müller, A. D., and Bush, M. B.: An 85-ka record of climate change in lowland Central America, Quaternary Sci. Rev., 27, 1152-1165, https://doi.org/10.1016/j.quascirev.2008.02.008, 2008.

Holmer, M. and Storkholm, P.: Sulphate reduction and sulphur cycling in lake sediments: a review, Freshwater Biol., 46, 431-451, 2001.

Horne, D. J.: Ostracoda, in: Microfossils, edited by: Selley, R. C., Cocks, M., and Plimer I. R., Encyclopedia of Geology, Amsterdeam, Boston, Heidelberg, Elsevier Academic Press, 453-463, 2005.

Iguchi, N. and Ikeda, T.: Effects of temperature on metabolism, growth and growth efficiency of Thysanoessa longipes (Crustacea: Euphausiacea) in the Japan Sea, J. Plankton Res., 27, 1-10, https://doi.org/10.1093/plankt/fbh146, 2004.

Ijaz, U. Z.: Collinearity and stepwise VIF selection: R script vs. 0.1, available at: http://www.r-bloggers.com/ collinearity-and-stepwise-vif-selection (last access: 4 December 2017), 2013.

Inoue, K., Hayes, D. M., Harris, J. L., and Christian, A. D.: Phylogenetic and morphometric analyses reveal ecophenotypic plasticity in freshwater mussels Obovaria jacksoniana and Villosa arkansasensis (Bivalvia: Unionidae), Ecol. Evol., 3, 2670-2683, https://doi.org/10.1002/ece3.649, 2013.

Keyer, D. and Aladin, N.: Noding in Cyprideis torosa and its causes, Studia Quaternaria, 21, 19-24, 2004.

Kim, Y., Mo, H.-H., Son, J., Lee, Y.-S., Lee, S.-E., and Cho, K.: Interactive effects of water $\mathrm{pH}$ and hardness levels on the growth and reproduction of Heterocypris incongruens (Crustacea: Ostracoda), Hydrobiologia, 753, 97-109, https://doi.org/10.1007/s10750-015-2199-z, 2015.

Koenders, A., Schön, I., Halse, S., and Martens, K.: Valve shape is not linked to genetic species in the Eucypris virens (Ostracoda, Crustacea) species complex, Zool. J. Linn. Soc., 180, 3646, https://doi.org/10.1111/zoj.12488, 2016.

Lacoul, P. and Freedman, B.: Environmental influences on aquatic plants in freshwater ecosystems, Environ. Rev., 14, 89-136, https://doi.org/10.1139/A06-001, 2006.

Lamers, L. P. M., Falla, S.-J., Samborska, E. M., Dulken, Ivo A. R. van, van Hengstum, G., and Roelofs, J. G. M.: Factors controlling the extent of eutrophication and toxicity in sulfatepolluted freshwater wetlands, Limnol. Oceanogr., 47, 585-593, https://doi.org/10.4319/lo.2002.47.2.0585, 2002.

Le Moullac, G. and Haffner, P.: Environmental factors affecting immune responses in Crustacea, Aquaculture, 191, 121-131, 2000.

Lewis Jr., M. L.: Tropical lakes: how latitude makes a difference, in: Perspectives in Tropical Limnology, edited by: Schiemer, F. and Boland, K. T., SPB Academic Publishing, Amsterdam, 43-64, 1996.

Loehr, J., Carey, J., O‘Hara, R. B., and Hik, D. S.: The role of phenotypic plasticity in responses of hunted thinhorn sheep ram horn growth to changing climate conditions, J. Evol. Biol., 23, 783790, https://doi.org/10.1111/j.1420-9101.2010.01948.x, 2010. 
Maan, M. E. and Seehausen, O.: Ecology, sexual selection and speciation, Ecol. Lett., 14, 591-602, https://doi.org/10.1111/j.14610248.2011.01606.x, 2011.

Mahler, D. L., Revell, L. J., Glor, R. E., and Losos, J. B.: Ecological opportunity and the rate of morphological evolution in the diversification of Greater Antillean anoles, Evolution, 64, 2731-2745, https://doi.org/10.1111/j.1558-5646.2010.01026.x, 2010.

Majoran, S., Agrenius, S., and Kucera, M.: The effect of temperature on shell size and growth rate in Krithe praetexta praetexta (Sars), Hydrobiologia, 419, 141-148, https://doi.org/10.1023/A:1003943617431, 2000.

Marco-Barba, J., Mesquita-Joanes, F., and Miracle, M. R.: Ostracod palaeolimnological analysis reveals drastic historical changes in salinity, eutrophication and biodiversity loss in a coastal Mediterranean lake, Holocene, 23, 556-567, https://doi.org/10.1177/0959683612466752, 2013.

Martens, K.: Effects of Temperature and Salinity on Postembryonic Growth in Mytilocypris henricae (Chapman) (Crustacea, Ostracoda), J. Crustacean Biol., 5, 258-272, 1985.

Martens, K., Rossetti, G., and Geiger, W.: Intraspecific morphological variability of limbs, in: Sex and Parthenogenesis: Evolutionary Ecology of Reproductive Modes in Non-Marine Ostracods, edited by: Martens, K., Backhuys Publishers, Leiden, 143-155, 1998.

Medley, P., Tibert, N., Patterson, W., Curran, H., Greer, L., and Colin, J.-P.: Paleosalinity history of middle Holocene lagoonal and lacustrine deposits in the Enriquillo Valley, Dominican Republic based on pore morphometrics and isotope geochemistry of ostracoda, Micropaleontology, 53, 409-419, 2007.

Meyer, J., Wrozyna, C., Gross, M., Leis, A., and Piller, W. E.: Morphological and geochemical variations of Cyprideis (Ostracoda) from modern waters of the northern Neotropics, Limnology, 18, 251-273, https://doi.org/10.1007/s10201-016-0504-9, 2016.

Meyer, J., Wrozyna, C., Leis, A., and Piller, W. E.: Modeling calcification periods of Cytheridella ilosvayi from Florida based on isotopic signatures and hydrological data, Biogeosciences, 14, 4927-4947, https://doi.org/10.5194/bg-14-4927-2017, 2017.

Mezquita, F., Roca, J. R., and Wansard, G.: Moulting, survival and calcification: the effects of temperature and water chemistry on an ostracod crustacean (Herpetocypris intermedia) under experimental conditions, Arch. Hydrobiol., 146, 219-238, 1999.

Mills, S. C., Oliver, T. H., Bradbury, R. B., Gregory, R. D., Brereton, T., Kühn, E., Kuussaari, M., Musche, M., Roy, D. B., Schmucki, R., Stefanescu, C., van Swaay, C., and Evans, K. L.: European butterfly populations vary in sensivity to weather across their geographical ranges, Global Ecol. Biogeogr., 26, 1374-1385, 2017.

Mitteroecker, P. and Bookstein, F.: The evolutionary role of modularity and integration in the hominoid cranium, Evolution, 62, 943-958, https://doi.org/10.1111/j.1558-5646.2008.00321.x, 2008.

Mitteroecker, P. and Bookstein, F.: Linear discrimination, ordination, and the visualization of selection gradients in modern morphometrics, J. Evol. Biol., 38, 100-114, 2011.

Mondal, N. C., Singh, V. P., Singh, V. S., and Saxena, V. K.: Determining the interaction between groundwater and saline water through groundwater major ions chemistry, J. Hydrol., 388, 100111, https://doi.org/10.1016/j.jhydrol.2010.04.032, 2010.
Mortsch, L. D. and Quinn, F. H.: Climate change scenarios for Great Lakes Basin ecosystem studies, Limnol. Oceanogr., 41, 903-911, 1996.

Müller, B. and Gächter, R.: Increasing chloride concentrations in Lake Constance: Characterization of sources and estimation of loads, Aquat. Sci., 74, 101-112, https://doi.org/10.1007/s00027011-0200-0, 2012.

Nakazawa, M.: fmsb: Functions for Medical Statistics Book with some Demographic Data, R package version 0.5.2, available at: http://CRAN.R-project.org/package=fmsb (last access: 4 December 2017), 2015.

Neubauer, T. A., Harzhauser, M., and Mandic, O.: Phenotypic evolution in a venerid bivalve species lineage from the late Middle Miocene Central Paratethys Sea: A multi-approach morphometric analysis, Biol. J. Linn. Soc., 110, 320-334, https://doi.org/10.1111/bij.12120, 2013.

Perry, E., Paytan, A., Pedersen, B., and Velazquez-Oliman, G.: Groundwater geochemistry of the Yucatan Peninsula, Mexico: Constraints on stratigraphy and hydrogeology, J. Hydrol., 367, 27-40, https://doi.org/10.1016/j.jhydrol.2008.12.026, 2009.

Perry, E., Velazquez-Oliman, G., and Marin, L.: The Hydrogeochemistry of the Karst Aquifer System of the Northern Yucatan Peninsula, Mexico, Int. Geol. Rev., 44, 191-221, https://doi.org/10.2747/0020-6814.44.3.191, 2002.

Pöckl, M.: Effects of temperature, age and body size on moulting and growth in the freshwater amphipods Gammarus fossarum and G. roeseli, Freshwater Biol., 27, 211-225, https://doi.org/10.1111/j.1365-2427.1992.tb00534.x, 1992.

Quinn, G. P. and Keough, M. J.: Experimental Design and Data Analysis for Biologists, Cambridge University Press, Cambridge, 537 pp., 2002.

$\mathrm{R}$ Core Team: R: A language and environment for statistical computing, R Foundation for Statistical Computing, Vienna, available at: http://www.R-project.org (last access: 4 December 2017), 2016.

Ramos, L., Cusminsky, G., Schwalb, A., and Alperin, M.: Morphotypes of the lacustrine ostracod Limnocythere rionegroensis Cusminsky \& Whatley from Patagonia, Argentina, shaped by aquatic environments, Hydrobiologia, 786, 137-148, https://doi.org/10.1007/s10750-016-2870-z, 2017.

Roca, J. R. and Wansard, G.: Temperature influence on development and calcification of Herpetocypris brevicaudata Kaufmann, 1900 (Crustacea: Ostracoda) under experimental conditions, Hydrobiologia, 347, 91-95, 1997.

Rohlf, F. J. and Slice, D.: Extensions of the Procrustes Method for the Optimal Superimposition of Landmarks, Syst. Zool., 39, 40 59, https://doi.org/10.2307/2992207, 1990.

Rohlf, F. J.: tpsDig: digitize landmarks and outlines, Department of Ecology and Evolution, State University of New York at Stony Brook, available at: http://life.bio.sunysb.edu/morph (last access: 16 April 2017), 2013.

Rohlf, F. J.: tpsRelw: relative warps analysis, Department of Ecology and Evolution, State University of New York at Stony Brook, available at: http://life.bio.sunysb.edu/morph (last access: 16 April 2017), 2015.

Rohlf, F. J.: tpsRelw: relative waprs analysis, Department of Ecology and Evolution, State University of New York at Stony Brook, available at: http://life.bio.sunysb.edu/morph (last access: 16 April 2017), 2016. 
Ruiz, F., Abad, M., Bodergat, A. M., Carbonel, P., RodríguezLázaro, J., González-Regalado, M. L., Toscano, A., García, E. X., and Prenda, J.: Freshwater ostracods as environmental tracers, Int. J. Environ. Sci. Technol., 10, 1115-1128, https://doi.org/10.1007/s13762-013-0249-5, 2013.

Sacks, L. A., Herman, J. S., and Kauffman, S. J.: Controls on High Sulfate Concentrations in the Upper Floridan Aquifer in Southwest Florida, Water Resour. Res., 31, 2541-2551, https://doi.org/10.1029/95WR02105, 1995.

Sanchez-Gonzalez, J. R., Baltanas, A., and Danielopol, D. L.: Patterns of morphospace occupation in recent Cypridoidea (Crustacea, Ostracoda), Rev. Esp. Micropaleontol., 36, 13-27, 2004.

Santos, I. R., Niencheski, F., Burnett, W., Peterson, R., Chanton, J., Andrade, C. F., Milani, I. B., Schmidt, A., and Knoeller, K.: Tracing anthropogenically driven groundwater discharge into a coastal lagoon from southern Brazil, J. Hydrol., 353, 275-293, https://doi.org/10.1016/j.jhydrol.2008.02.010, 2008.

Schmidt, N., Lipp, E. K., Rose, J. B., and Luther, M. E.: ENSO Influences on Seasonal Rainfall and River Discharge in Florida, J. Clim., 14, 615-628, 2001.

Van Doninck, K., Schön, I., Martens, K., and Goddeeris, B.: The life-cycle of the asexual ostracod Darwinula stevensoni (Brady \& Robertson, 1870) (Crustacea, Ostracoda) in a temporate pond, Hydrobiologia, 500, 331-340, https://doi.org/10.1023/A:1024656920904, 2003.

van der Meeren, T., Verschuren, D., Ito, E., and Martens, K.: Morphometric techniques allow environmental reconstructions from low-diversity continental ostracode assemblages, J. Paleolimnol., 44, 903-911, https://doi.org/10.1007/s10933-010-9463-z, 2010.

van Harten, D.: Size and environmental salinity in the modern euryhaline ostracod Cyprideis torosa (Jones, 1850), a biometrical study, Palaeogeogr. Palaeocl., 17, 35-48, 1975.

van Harten, D.: Variable noding in Cyprideis torosa (Ostracoda, Crustacea): an overview, experimental results and a model from Catastrophe Theory, Hydrobiologia, 419, 131-139, 2000.

Vesper, B.: Ein Beitrag zur Ostracodenfauna Schleswig-Holsteins, Mitt. Hamb. Zool. Mus. Inst., 72, 97-108, 1975.

Viero, A. P., Roisenberg, C., Roisenberg, A., and Vigo, A.: The origin of fluoride in the granitic aquifer of Porto Alegre, Southern Brazil, Environ. Geol, 56, 1707-1719, https://doi.org/10.1007/s00254-008-1273-5, 2009.

von Daday, E.: Süsswasser-Mikrofauna Paraguays, in: Untersuchungen über die Süsswasser Mikrofauna Paraguays, edited by: Chun, C., Zoologica, 44, 1-349, 1905.

Wagner, P. J. and Erwin, D. H.: Patterns of convergence in general shell form among Paleozoic gastropods, Paleobiology, 32, 316337, https://doi.org/10.1666/04092.1, 2006.
Walsh, C. and Mac Nally, R.: hier.part: Hierarchical Partitioning: R package version 1.0-4, available at: http://CRAN.R-project.org/ package=hier.part (last access: 4 December 2017), 2013.

Weihrauch, D., McNamara, J. C., Towle, D. W., and Onken, H.: Ion-motive ATPases and active, transbranchial $\mathrm{NaCl}$ uptake in the red freshwater crab, Dilocarcinus pagei (Decapoda, Trichodactylidae), J. Exp. Biol., 207, 4623-4631, https://doi.org/10.1242/jeb.01333, 2004.

Whitehead, P. G., Wilby, R. L., Battarbee, R. W., Kernan, M., and Wade, A. J.: A review of the potential impacts of climate change on surface water quality, Hydrol. Sci. J., 54, 101-123, https://doi.org/10.1623/hysj.54.1.101, 2009.

WorldClim: WorldClim-Global Climate Data, available at: http:// worldclim.org/version2, last access: 25 March 2017.

Wrozyna, C., Piller, W. E., and Gross, M.: Morphotypes of Cytheridella ilosvayi (Ostracoda) detected by soft and hard part analyses, Crustaceana, 87, 1043-1071, https://doi.org/10.1163/15685403-00003342, 2014.

Wrozyna, C., Neubauer, T. A., Meyer, J., and Piller, W. E.: Shape Variation in Neotropical Cytheridella (Ostracoda) Using Semilandmarks-Based Geometric Morphometrics: A Methodological Approach and Possible Biogeographical Implications, Plos ONE, 11, e0168438, https://doi.org/10.1371/journal.pone.0168438, 2016.

Wrozyna, C., Meyer, J., Gross, M., Ramos, M. I. F., and Piller, W. E.: Definition of regional ostracod (Cytheridella) morphotypes by use of landmark-based morphometrics, Freshwater Sci., 37, 573-592, https://doi.org/10.1086/699482, 2018a.

Wrozyna, C., Meyer, J., Gross, M., Ramos, M. I. F., and Piller, W. E.: Cryptic morphospecies of the C. ilosvayi group in the Neotropics, PlosONE, under review, 2018b.

Yin, Y., Geiger, W., and Martens, K.: Effects of genotype and environment on phenotypic variability in Limnocythere inopinata (Crustacea: Ostracoda), Hydrobiologia, 400, 85-114, 1999.

Yin, Y., Li, W., Yang, X., Wang, S., Li, S., and Xia, W.: Morphological responses of Limnocythere inopinata (Ostracoda) to hydrochemical environment factors, Sci. China Ser. D, 44, 316-323, 2001.

Zieritz, A. and Aldridge, D. C.: Identification of ecophenotypic trends within three European freshwater mussel species (Bivalvia: Unionoida) using traditional and modern morphometric techniques, Biol. J. Linn. Soc., 98, 814-825, https://doi.org/10.1111/j.1095-8312.2009.01329.x, 2009. 